\title{
A composite mouse model of aplastic anemia complicated with iron overload
}

\author{
DIJIONG WU ${ }^{1 *}$, XIAOWEN WEN ${ }^{2 *}$, WENBIN LIU ${ }^{1}$, LINLONG XU $^{3}$, BAODONG YE $^{1}$ and YUHONG ZHOU \\ ${ }^{1}$ Department of Hematology, First Affiliated Hospital of Zhejiang Chinese Medical University, \\ National Clinical Research Base of Traditional Chinese Medicine, Hangzhou, Zhejiang 310006; \\ ${ }^{2}$ Department of Internal Medicine, Central Hospital of Jinhua Affiliated to Zhejiang University, Jinhua, Zhejiang 321001; \\ ${ }^{3}$ First Clinical Medical College, Zhejiang Chinese Medical University, Hangzhou, Zhejiang 310053, P.R. China
}

Received August 18, 2016; Accepted September 19, 2017

DOI: $10.3892 / \mathrm{etm} .2017 .5523$

\begin{abstract}
Iron overload is commonly encountered during the course of aplastic anemia (AA), but no composite animal model has been developed yet, which hinders drug research. In the present study, the optimal dosage and duration of intraperitoneal iron dextran injection for the development of an iron overload model in mice were explored. A composite model of AA was successfully established on the principle of immune-mediated bone marrow failure. Liver volume, peripheral hemogram, bone marrow pathology, serum iron, serum ferritin, pathological iron deposition in multiple organs (liver, bone marrow, spleen), liver hepcidin, and bone morphogenetic protein 6 (BMP6), SMAD family member 4 (SMAD4) and transferrin receptor 2 (TfR2) mRNA expression levels were compared among the normal control, AA, iron overload and composite model groups to validate the composite model, and explore the pathogenesis and features of iron overload in this model. The results indicated marked increases in iron deposits, with significantly increased liver/body weight ratios as well as serum iron and ferritin in the iron overload and composite model groups as compared with the normal control and AA groups $(\mathrm{P}<0.05)$. There were marked abnormalities in iron regulation gene expression between the AA and composite model groups, as seen by the significant decrease of hepcidin expression in the liver $(\mathrm{P}<0.01)$ that paralleled the changes in BMP6, SMAD4, and TfR2. In summary, a composite mouse model with iron overload and AA was successfully
\end{abstract}

Correspondence to: Dr Dijiong $\mathrm{Wu}$ or $\mathrm{Dr}$ Baodong $\mathrm{Ye}$, Department of Hematology, First Affiliated Hospital of Zhejiang Chinese Medical University, National Clinical Research Base of Traditional Chinese Medicine, 54 Youdian Road, Hangzhou, Zhejiang 310006, P.R. China

E-mail:wdj850@163.com

E-mail: yebaodong_zjtcm@163.com

*Contributed equally

Key words: aplastic anemia, iron overload, mouse, animal model established, and AA was indicated to possibly have a critical role in abnormal iron metabolism, which promoted the development of iron deposits.

\section{Introduction}

Aplastic anemia (AA) is a common hematologic disease that is characterized by hematopoietic failure of the bone marrow and pancytopenia of the peripheral blood, and patients typically suffer from anemia, infection and hemorrhage (1). It is reported that the incidence of AA is $2 / 10^{6}$ per year in western countries, while in China, the rate is nearly triple $\left(\sim 7.4 / 10^{6}\right)$; chronic AA comprises almost $80 \%$ of AA in China (2). During the clinical practice, it was demonstrated that the majority of patients with AA exhibit iron overload secondary to long-term blood transfusions due to moderate and severe anemia (3). Iron overload and chelation therapy have recently been important areas of research in hematologic diseases, particularly in hematopoietic failure diseases $(4,5)$. Iron chelation therapy has been recommended in AA practice guidelines due to its role in protecting major organs, promoting hematopoiesis, delaying disease progression and improving the quality of life (6). Nevertheless, few drugs are currently used in clinical practice for iron chelation therapy in AA. These drugs may also lead to thrombocytopenia or increase the susceptibility to infection as a side effect (7). Furthermore, some effective drugs that are available are too expensive for some patients in less developed countries, including deferasirox (8-10). Therefore, it is of clinical importance to identify effective and low-cost iron chelation agents and validate their effects. Available models of aplastic anemia or iron overload have been constructed (11-14); however, no animal model of AA complicated with iron overload currently exists, which hinders drug research and development. The present study reports a feasible composite mouse model of AA complicated with iron overload.

\section{Materials and methods}

Animals. A total of 64 clean-grade inbred female BALB/c mice (weight, 17-20 g) aged 6-8 weeks, and 5 female DBA/2 mice (weight, 15-20 g) aged 6-14 weeks were provided and fed by the Laboratory Animal Center of Zhejiang Chinese 
Medical University (Hangzhou, China). Mice were housed using a stocking density of 3-5 mice per cage in a temperature and humidity controlled room $\left(23 \pm 1^{\circ} \mathrm{C}, 55 \pm 5 \%\right)$ and exposed to a 12-h light/dark cycle. All animals had ad libitum access to normal chow and water. The experiments were performed according to the National Institute of Health Guide for the Care and Use of Laboratory Animals [revised 1996 (11)] and were approved by the Animal Management and Ethics Committee of Zhejiang Chinese Medical University (no. ZSLL-2013-108).

Reagents. The following reagents were used in the present study: Iron dextran (Sigma-Aldrich; Merck KGaA, Darmstadt, Germany); serum iron (SI) detection kit (cat. no. A039-1; Nanjing Jiancheng Bioengineering Institute, Nanjing, China); and serum ferritin (SF) ELISA kit (cat. no. CSB-E05187h; Cusabio Biotech Co., Ltd., Wuhan, China).

Animal grouping and treatments. BALB/c mice were randomly assigned to the following groups: Normal control (group A, n=8), AA (group B, $\mathrm{n}=8$ ), iron overload (group C, $\mathrm{n}=24$ ), and composite model (group $\mathrm{D}, \mathrm{n}=24$ ). Furthermore, groups $\mathrm{C}$ and $\mathrm{D}$ were divided into three subgroups $(\mathrm{C} 1, \mathrm{C} 2$, and $\mathrm{C} 3$; and D1, D2 and D3, $\mathrm{n}=8$ respectively), according to the administration frequency and single dose of iron dextran $(200 \mathrm{mg} / \mathrm{kg} /$ week x 10 weeks, $250 \mathrm{mg} / \mathrm{kg} /$ week x 8 weeks or $333 \mathrm{mg} / \mathrm{kg} /$ weekx 6 weeks, respectively). Following evaluation of the iron-overload parameters (SI and SF), the best iron-loaded model in Group D was used to develop the composite model of AA.

Duplication of iron-overloaded model. Groups C and D were administered with the corresponding dosages of iron dextran via intraperitoneal injection, whereas groups $\mathrm{A}$ and $\mathrm{B}$ were administered the equivalent volume of normal saline (NS).

Validation of iron-overloaded model. Following administration of the iron dextran injection, blood samples were collected from the orbital veins of mice in groups $\mathrm{C}$ and $\mathrm{D}$ for the detection of SI and SF, and for the determination of the optimal iron dextran dosage and cycle for duplication of the iron-overloaded model.

Duplication of the mouse model of AA. Following identifying the optimal iron-overloaded model, the optimal iron-overloaded subgroups of Groups D and B were used for the duplication of the mouse AA model based on previous methods used by the present authors (15). DBA/2 mice were euthanized via cervical dislocation and the thymuses were harvested using aseptic techniques for the preparation of cell suspensions of $5 \times 10^{6}$ cells $/ \mathrm{ml}$. The cells were washed in phosphate buffered saline (PBS) twice and suspended in saline prior to injection. Groups B and D were treated with whole-body irradiation with ${ }^{60} \mathrm{Co} 6.0 \mathrm{~Gy}$ at $1 \mathrm{~Gy} / \mathrm{min}$, after which $0.2 \mathrm{ml}$ prepared cell suspensions was injected into each mouse via the caudal vein within $4 \mathrm{~h}$.

Sample collection. The completion of duplication of the mouse AA model in groups B and D was defined as day 0. Blood was collected from the orbital veins of the mice in the four groups for routine testing on days +10 and +30 . Blood, liver, heart, spleen and bilateral femurs were extracted from randomly chosen mice $(n=4)$ from the groups on day +15 following overnight fasting and euthanasia via cervical dislocation.

Detection of peripheral hemogram. Blood tests were performed at the Department of Laboratory Medicine of Zhejiang Provincial Hospital of Traditional Chinese Medicine (Hangzhou, China). Peripheral blood smears were prepared and after Wright-Giemsa staining, peripheral hemogram detection was performed using manual classification and counting protocols (16) under a light microscope (CX31RTSF; Olympus Optical Co., Ltd., Tokyo, Japan) at a magnification of $x 400$.

Liver/body weight ratio testing. Livers were collected from the mice immediately following euthanasia and washed with NS. They were subsequently wiped dry with filter papers and weighed, and the liver/body weight ratio was calculated.

Pathomorphological observation. For all groups, the liver, spleen, and unilateral femur were fixed in a $10 \%$ formalin solution under room temperature within $30 \mathrm{~min}$ after collection for $24 \mathrm{~h}$. The femur was decalcified by soaking in 5\% nitric acid solution for 7-12 h. All tissues were dehydrated, paraffin-embedded, cut into sections (5- $\mu \mathrm{m}$-thick), stained at room temperature with hematoxylin and eosin (hematoxylin staining for 5-10 $\mathrm{min}$, and eosin staining for 1-3 min)/iron (prussian blue staining for $20 \mathrm{~min}$ and redyed with Sudan red for $1 \mathrm{~min}$ ), and observed for bone marrow pathomorphology and multiple organ iron deposition under light microscopy with a $\times 400$ magnification.

Detection of SI content. Blood plasma $(0.5 \mathrm{ml})$ was collected for the detection of SI content by absorption spectrophotometry using a microplate reader with the SI detection kit according to the manufacturer's protocol and the following equation using the absorbance of the detection tube (Ad), absorbance of the blank tube $(\mathrm{Ab})$ and the absorbance of the standard tube (As):

$$
\mathrm{SI}=\frac{A d-A b}{A s-A b} \times \text { standard concentration }(35.81 \mu \mathrm{mol} / \mathrm{l})
$$

Detection of $S F$. A total of $0.5 \mathrm{ml}$ serum was taken from each group (1.5-2 $\mathrm{ml}$ was collected previously) for the detection of SF level using the ELISA kit according to the manufacturer's protocol. Following reaction termination, optical density (OD) values were detected via microplate reader at $450 \mathrm{~nm}$. A standard curve was plotted using CurveExpert Professional software (version 1.4, developed by Daniel G. Hyams, http://s 91928265.onlinehome.us/curveexpert/), and sample concentrations were calculated based on the OD values.

Detection of liver transferrin receptor 2 (TfR2), hepcidin, bone morphogenic protein 6 (BMP6) and SMAD family member 4 (SMAD4) expression levels using reverse transcription-quantitative polymerase chain reaction (RT-qPCR). Total mRNA was extracted from hepatocytes using the TRIzol (Invitrogen; Thermo Fisher Scientific, Inc., Waltham, MA, USA) one-step method and used for RT. RT was performed using PrimeScript ${ }^{\mathrm{TM}}$ RT reagent kit with gDNA Eraser (Takara 
Table I. Primers of Hepcidin, BMP6, SMAD4, TfR2 and GAPDH.

\begin{tabular}{|c|c|c|c|}
\hline Gene & Direction & Sequence $\left(5^{\prime}-3^{\prime}\right)$ & Length (bp) \\
\hline \multirow[t]{2}{*}{ Hepcidin } & $\mathrm{F}$ & CTGAGCAGCACCACCTATCTC & \multirow[t]{2}{*}{205} \\
\hline & $\mathrm{R}$ & TGGCTCTAGGCTATGTTTTGC & \\
\hline \multirow[t]{2}{*}{ BMP6 } & $\mathrm{F}$ & ATGGCAGGACTGGATCATTGC & \multirow[t]{2}{*}{54} \\
\hline & $\mathrm{R}$ & CCATCACAGTAGTTGGCAGCG & \\
\hline \multirow[t]{2}{*}{ SMAD4 } & $\mathrm{F}$ & AGGTGGCCTGATCTACACAAG & \multirow[t]{2}{*}{111} \\
\hline & $\mathrm{R}$ & ACCCGCTCATAGTGATATGGATT & \\
\hline \multirow[t]{2}{*}{ TfR2 } & $\mathrm{F}$ & АТTСТССТТТСТСССТСТTТ & \multirow[t]{2}{*}{253} \\
\hline & $\mathrm{R}$ & GCTGTCCATCTCACTCTCTA & \\
\hline \multirow[t]{2}{*}{ GAPDH } & $\mathrm{F}$ & CCTCAAGATTGTCAGCAAT & \multirow[t]{2}{*}{141} \\
\hline & $\mathrm{R}$ & CCATCCACAGTCTTCTGAGT & \\
\hline
\end{tabular}

BMP6, bone morphogenic protein 6; SMAD 4, SMAD family member 4; TfR2, transferrin receptor 2; F, forward, R, reverse.

Biotechnology Co., Ltd., Dalian, China; cat. no. RR047A) in a 20- $\mu$ l reaction volume. Briefly, $1 \mu \mathrm{g}$ total RNA from hepatocytes, $2 \mu 1$ 5X gDNA Eraser Buffer, $1 \mu 1$ gDNA Eraser and nuclease-free water were mixed well in a total volume of $10 \mu \mathrm{l}$ and incubated for $2 \mathrm{~min}$ at $42^{\circ} \mathrm{C}$ to eliminate genomic DNA. For the synthesis of cDNA, $4 \mu 15 \mathrm{X}$ PrimeScript Buffer 2, $1 \mu$ l PrimeScript RT Enzyme Mix, $1 \mu$ l RT Primer Mix and $4 \mu \mathrm{l}$ nuclease-free water were susbsequently added, and the reaction mixtures were subjected to the following conditions: $37^{\circ} \mathrm{C}$ for $15 \mathrm{~min}$, followed by $85^{\circ} \mathrm{C}$ for $5 \mathrm{sec}$, held at $4^{\circ} \mathrm{C}$ and stored at $-20^{\circ} \mathrm{C}$ until qPCR amplification. qPCR was performed using SYBR ${ }^{\circledR}$ Premix Ex TagTM II (Takara Biotechnology Co., Ltd.; cat. no. RR820A) in a 20- $\mu$ l reaction volume. Each reaction was comprised of $2 \mu \mathrm{l}$ of the cDNA solution, $10 \mu \mathrm{l}$ of $\mathrm{SYBR}^{\circledR}$ Premix Ex TagTM (2X), $1.6 \mu \mathrm{l}$ of primers, $0.4 \mu \mathrm{l}$ of ROX Reference Dye and $6 \mu \mathrm{l}$ of nuclease-free water. The thermocycling protocol was as follows: $95^{\circ} \mathrm{C}$ for $30 \mathrm{sec}$ for initial denaturation; 40 cycles of $95^{\circ} \mathrm{C}$ for $5 \mathrm{sec}$ and $60^{\circ} \mathrm{C}$ for $30 \mathrm{sec}$ for PCR; and $95^{\circ} \mathrm{C}$ for $15 \mathrm{sec}, 60^{\circ} \mathrm{C}$ for $30 \mathrm{sec}$ and $95^{\circ} \mathrm{C}$ for $15 \mathrm{sec}$ for separation. The $\Delta \mathrm{Cq}$ value $\left(\mathrm{Cq}_{\text {target genes }}-\mathrm{Cq}_{\text {reference gene }}\right)$ of each sample was calculated using the relatively quantitative method and $2^{-\Delta \Delta \mathrm{Cq}}$ was calculated as follows: $\Delta \Delta \mathrm{Cq}=\Delta \mathrm{Cq}_{\text {experimental group }}-\Delta \mathrm{Cq}_{\text {control group }}$ (17). GAPDH was used as a reference gene and primer sequences are provided in Table I.

Statistical analysis. Data were analyzed using SPSS 17.0 (SPSS, Inc., Chicago, IL, USA). All experiment was repeated in triplicate and data are presented as the mean \pm standard error of the mean One way analysis of variance was employed to compare two groups of normally distributed data and followed by a post hoc Newman-Keuls test. $\mathrm{P}<0.05$ was considered to indicate a statistically significant difference.

\section{Results}

Comparison of iron loads between iron-overloaded models of different dosage regimens. The results indicated that all iron overload subgroups (C1-C3) had significantly higher SI than the normal control group $(164.40 \pm 22.44,151.92 \pm 42.58$, and $129.56 \pm 14.10$ vs. $99.70 \pm 15.46 ; \mathrm{C} 1, \mathrm{P}<0.01$ vs. control;

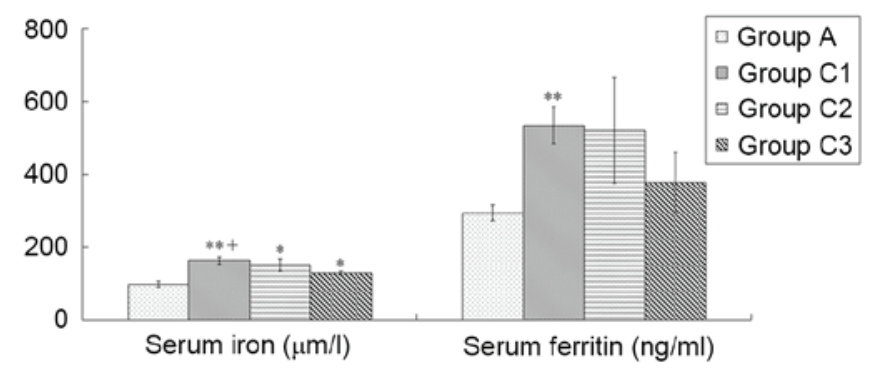

Figure 1. Comparison of iron loads between iron-overloaded models of different dosage regimens. According to the injection frequency and single dose volumes, mice were divided into three iron overload groups (C1-C3), with the administration of iron dextran $200 \mathrm{mg} / \mathrm{kg} /$ week for 10 weeks, $250 \mathrm{mg} / \mathrm{kg} /$ week for 8 weeks and $333 \mathrm{mg} / \mathrm{kg} /$ week for 6 weeks, respectively. Normal controls in group A were administered the equivalent volume of normal saline. Data are presented as the mean \pm standard error of the mean $(\mathrm{n}=8) .{ }^{*} \mathrm{P}<0.05,{ }^{* *} \mathrm{P}<0.01$ vs. group $\mathrm{A} ;{ }^{+} \mathrm{P}<0.01$ vs. group $\mathrm{C} 3$.

$\mathrm{C} 2$ and $\mathrm{C} 3, \mathrm{P}<0.05$ vs. control). Group $\mathrm{C} 1$ had a significantly higher SI level than Group C3 ( $\mathrm{P}=0.012)$; however, other inter-group comparisons showed no significant differences. The iron-overloaded group $\mathrm{C} 1$ had a significantly higher SF than the normal control group (534.43 \pm 114.35 vs. $294.89 \pm 43.80 ; \mathrm{P}=0.006)$, whereas the other iron-overloaded groups were not significantly different from the control group (Fig. 1). As a result, group C1 was selected as the optimal composite model for the establishment of the composite model of AA complicated by iron overload.

Comparison of peripheral hemograms between groups during establishment of the composite model. A previous report by the present authors (15) indicated that the peripheral hemograms of the immune-mediated AA group peaked at $\sim$ day +10 . Therefore, in the present study the peripheral hemograms of the AA model were detected at day +10 . The results demonstrated that the AA and composite model groups had a significantly lower white blood cell count (WBC), hemoglobin ( $\mathrm{Hb})$, red blood cell count (RBC), and platelet count (PLT) compared with the normal control and iron overload groups (all $\mathrm{P}<0.01$ ), whereas other inter-group comparisons showed no significant differences (Fig. 2). 


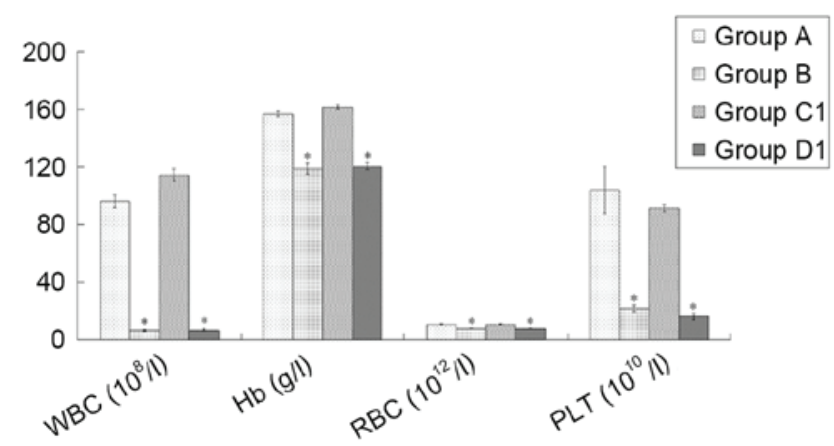

Figure 2. Comparison of peripheral hemograms among groups at 10 days following the establishment of the composite model. The routine blood tests were performed using manual classification and counting protocols. Data are presented as the mean \pm standard error of the mean $(n=8)$. ${ }^{*} \mathrm{P}<0.01$ vs. groups $\mathrm{A}$ and $\mathrm{C} 1$. A, normal control; $\mathrm{B}$, aplastic anemia; $\mathrm{C} 1$, iron overload; D1, composite model; WBC, white blood cell count; Hb, hemoglobin; RBC, red blood cell count; PLT, platelet count.

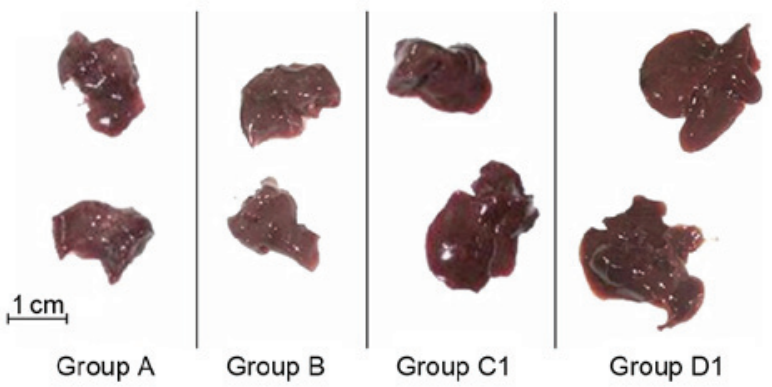

Figure 3. General morphology of spleens in all groups. Larger spleen volumes were observed in groups $\mathrm{C} 1$ and $\mathrm{D} 1$ compared with groups A and B. A normal control; B, aplastic anemia; C1, iron overload; D1, composite model.

Comparison of liver/body weight ratios between groups. The results showed that the iron overload and composite model groups had significantly higher liver/body weight ratios than the other two groups (all $\mathrm{P}<0.01$, except group $\mathrm{C} 1$ vs. $\mathrm{A}, \mathrm{P}<0.05$ ), whereas the ratios were not significantly different between groups A and B or between groups $\mathrm{Cl}$ and D1 (Fig. 3; Table II).

Bone marrow pathology observations. The present results indicated that groups B and D1 had notably poorer bone marrow hyperplasia than groups $\mathrm{A}$ and $\mathrm{C} 1$, and that the hyperplasia was more marked in group D1. Compared with groups A and C1, groups B and D1 exhibited more fat granules, lower hematopoietic cell ratios and fewer bone marrow megakaryocytes (Fig. 4).

Iron staining of multiple organs (liver, bone marrow and spleen). The present results demonstrated that there was no notable iron deposition in the liver (Fig. 5A-D) or bone marrow (Fig. 5E-H) of groups A and B; however, there was marked deposition in the iron-overloaded groups $\mathrm{C} 1$ and D1. Iron was not markedly deposited in the spleen even following iron overload (Fig. 5I-L).

Comparison of iron overload-associated parameters. SI levels were $134.34 \pm 44.27,195.33 \pm 37.71,278.45 \pm 51.32$ and $269.38 \pm 38.14 \mu \mathrm{mol} / 1$ in groups $\mathrm{A}, \mathrm{B}, \mathrm{C} 1$ and D1 on
Table II. Comparison of liver/body weight ratios among groups.

\begin{tabular}{lc} 
Group & Liver/body weight ratio (\%) \\
\hline A & $4.43 \pm 0.34$ \\
B & $4.46 \pm 0.17$ \\
C1 & $7.12 \pm 0.35^{\mathrm{a}, \mathrm{c}}$ \\
D1 & $7.53 \pm 0.31^{\mathrm{b}, \mathrm{c}}$
\end{tabular}

Data are presented as the mean \pm standard error of the mean $(n=8)$. ${ }^{\mathrm{a}} \mathrm{P}<0.05,{ }^{\mathrm{b}} \mathrm{P}<0.01$ vs. group $\mathrm{A} ;{ }^{\mathrm{c}} \mathrm{P}<0.01$ vs. group $\mathrm{B}$. A, normal control; $\mathrm{B}$, aplastic anemia; $\mathrm{C} 1$, iron overload; D1, composite model.

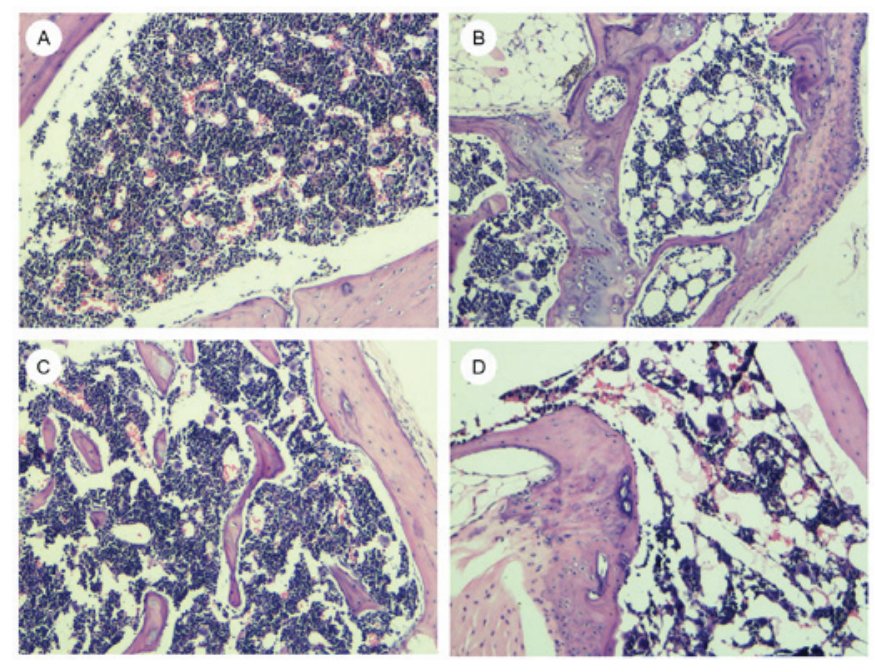

Figure 4. Morphological changes of bone marrow in (A-D) groups A, B, C1 and D1. Following hematoxylin-eosin staining, samples were observed under a light microscope and images were captured at $\mathrm{x} 400$ magnification. Poorer hyperplasia was observed in group B and D1 as indicated by the increase in number of fat granules, lower hematopoietic cell ratio and fewer marrow megakaryocytes.

day +15 , respectively. and the corresponding SF levels were $394.26 \pm 58.05,499.40 \pm 36.98,656.75 \pm 49.96$ and $946.28 \pm 54.48 \mathrm{ng} / \mathrm{ml}$, respectively. On day +15 , compared with group A, the other three groups exhibited significantly higher SI and SF values (all $\mathrm{P}<0.01$; except group B SI, $\mathrm{P}<0.05$ ); compared with group $\mathrm{B}$, groups $\mathrm{C} 1$ and $\mathrm{D} 1$ had significantly higher SI (both $\mathrm{P}<0.05$ ) and SF values (both $\mathrm{P}<0.01$ ); and compared with group $\mathrm{C} 1$, group $\mathrm{D} 1$ had a significantly higher $\mathrm{SF}$ value $(\mathrm{P}<0.01$; Fig. 6$)$. In group $\mathrm{D} 1$, the changes in the SI and $\mathrm{SF}$ levels between days +15 and +30 were also compared. The results demonstrated that the SI and SF levels in group D1 were $266.08 \pm 37.58 \mu \mathrm{mol} / 1$ and $1,006.17 \pm 118.36 \mathrm{ng} / \mathrm{ml}$ on day +30 , respectively. SI and SF remained stable without continuing iron dextran, and no significant differences were observed between these time points (Fig. 7).

Comparison of hepcidin, BMP6, SMAD4, and TfR2 mRNA expression levels. The present results demonstrated that groups $\mathrm{B}, \mathrm{C} 1$, and $\mathrm{D} 1$ had significantly lower hepcidin (all $\mathrm{P}<0.01$ ), BMP6 (groups B and D1, $\mathrm{P}<0.01$; group $\mathrm{C} 1, \mathrm{P}<0.05$ ), and 

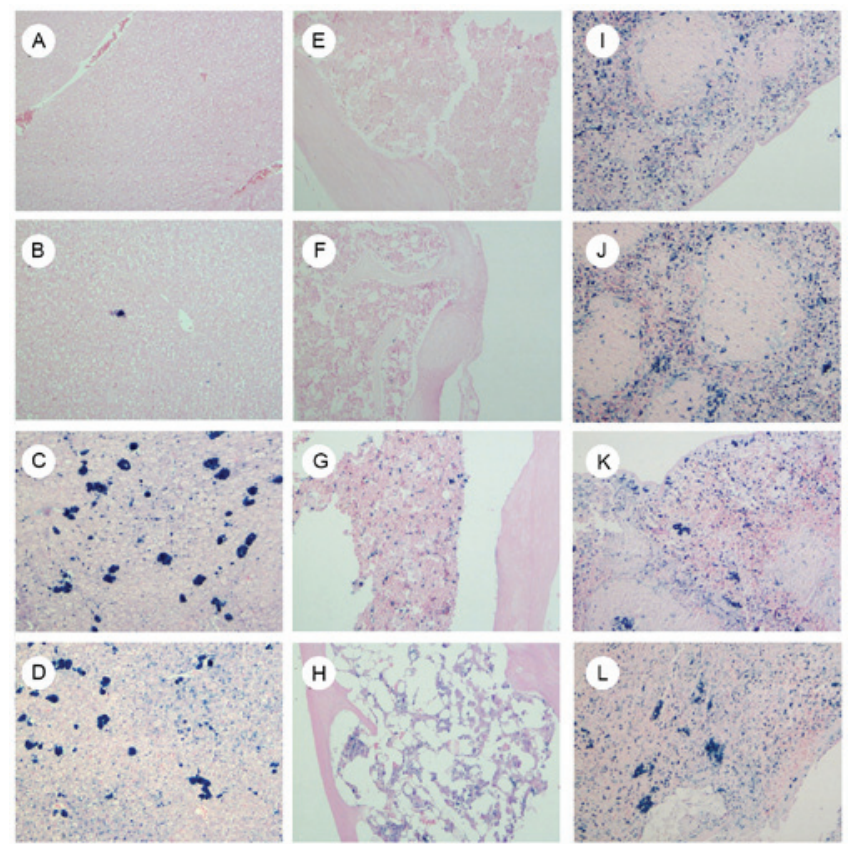

Figure 5. Iron deposition of multiple organs in groups A, B, C1 and D1 Following prussian blue staining, slides were redyed with Sudan red, observed under a light microscope and images were captured at x400 magnification. Images show (A-D) liver, (E-H) bone marrow and (I-L) spleen tissues in groups A, B, C1 and D1, respectively. Markedly increased iron deposits were observed in liver and bone marrow of groups $\mathrm{C} 1$ and D1, but not in groups A and B. A, normal control; B, aplastic anemia; C1, iron overload; D1, composite model.

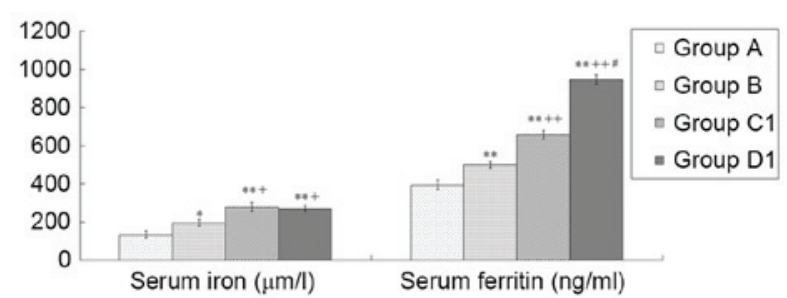

Figure 6. Comparison of serum iron and ferritin levels among different groups. Serum iron and ferritin levels among groups A, B, C1 and D1 were detected. Data are presented as the mean \pm standard error of the mean $(n=8)$. ${ }^{*} \mathrm{P}<0.05,{ }^{* *} \mathrm{P}<0.01$ vs. group $\mathrm{A} ;{ }^{+} \mathrm{P}<0.05,{ }^{++} \mathrm{P}<0.01$ vs. group $\mathrm{B} ;{ }^{*} \mathrm{P}<0.01$ vs. group $\mathrm{C} 1$. A, normal control; B, aplastic anemia; C1, iron overload; D1, composite model.

SMAD4 (all P<0.01) mRNA expression levels than group A, whereas those of group $\mathrm{C} 1$ were significantly higher than those of groups B and D1 (all $\mathrm{P}<0.01$ ). Furthermore, group B had significantly lower hepcidin $(\mathrm{P}<0.05)$ and SMAD4 $(\mathrm{P}<0.01)$ mRNA expression levels than group D1. Compared with group A, groups B and D1 had significantly downregulated TfR2 mRNA expression levels (both, $\mathrm{P}<0.05$ ), whereas group $\mathrm{C} 1$ had a significantly higher expression level than group B $(\mathrm{P}<0.01$; Fig. 8).

\section{Discussion}

At present, there is no consensus on the diagnostic criteria of iron overload. Iron overload is typically diagnosed if the patient receives erythrocyte transfusion $>20-40 \mathrm{U}$ or exhibits

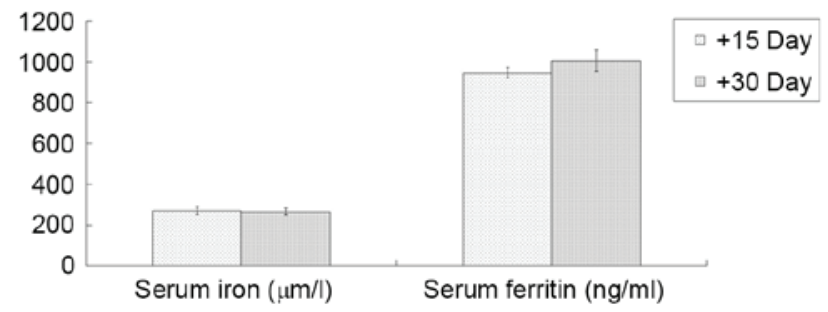

Figure 7. Comparison of serum iron and ferritin level changes in the composite model group. Serum iron and ferritin levels in the composite model group were detected on days +15 and +30 . Data are presented as the mean \pm standard error of the mean $(n=4)$.

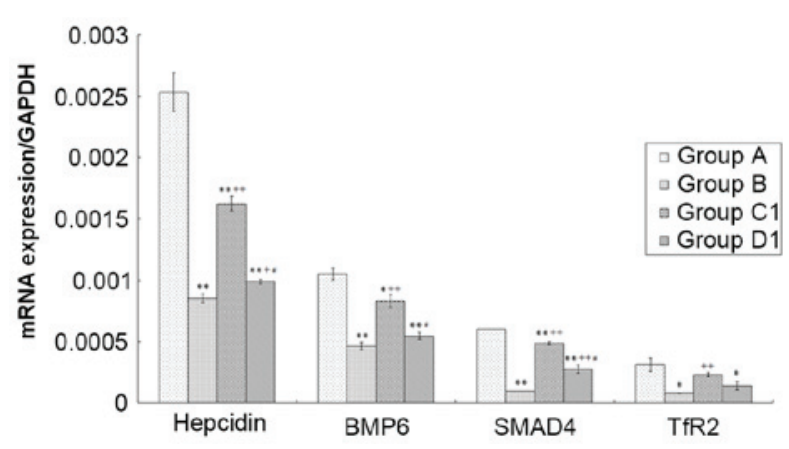

Figure 8. Analysis of hepcidin, BMP6, SMAD4 and TfR2 mRNA expression levels among different groups. Total mRNA was isolated and reverse transcribed to cDNA, following which a reverse transcription-quantitative polymerase chain reaction protocol was performed. Data are presented as the mean \pm standard error of the mean $(\mathrm{n}=8)$. ${ }^{*} \mathrm{P}<0.05,{ }^{* *} \mathrm{P}<0.01$ vs. group $\mathrm{A} ;{ }^{+} \mathrm{P}<0.05,{ }^{++} \mathrm{P}<0.01$ vs. group $\mathrm{B} ;{ }^{~} \mathrm{P}<0.01$ vs. group $\mathrm{C} 1$. A, normal control; $\mathrm{B}$, aplastic anemia; C1, iron overload; D1, composite model; BMP6, bone morphogenic protein 6; SMAD 4, SMAD family member 4; TfR2, transferrin receptor 2 .

an SF>500-2,500 $\mu \mathrm{g} / 1$ (18). The incidence of iron overload is reportedly $13 \%$ in acquired AA patients; however, only $22 \%$ of these patients have a clear past history of blood transfusion (3). Iron overload is associated with excessive iron uptake, iron metabolism disorders, gene mutations and other factors (19). The establishment of an animal model of AA complicated by iron overload may help elucidate pathological changes and facilitate the screening of potential drug therapies.

The current mouse model of immune-mediated AA is well established and easy to duplicate; therefore, it is used for studies of pathogenesis and trials of drug efficacy $(20,21)$. Methods for the establishment of the iron overload model typically include iron injection (using iron dextran or iron sucrose), carbonyl iron feed additive method and gene knockout; among these, the carbonyl iron feed additive method is time-consuming, the obtained model is unstable, and the gene knockout has complicated experimental procedures and high requirements (22-25). Conversely, the iron injection has the advantages of a short duplication cycle, high success rate, and good stability, thus it is used by many researchers $(14,26,27)$ to establish a secondary iron overload model (22). In the present study, a composite model of AA complicated by iron overload was established using a combination of iron dextran injection and an immune-mediated method.

Given the long period required for iron overload model establishment and the additional risk of death due to iron 
dextran administration in AA model mice, it was not until the successful duplication of iron overload that the AA model was developed. As there are disagreements regarding the dosage and frequency of intraperitoneal injections of iron dextran $(8,9)$, mice were randomly divided into three experimental groups and received the same total injection dose $\left(2.0 \times 10^{3} \mathrm{mg} / \mathrm{kg}\right)$ according to different dosage and injection frequency. Subsequently, the composite model of AA was established based on group $\mathrm{C} 1$ as this injection protocol ( $200 \mathrm{mg} / \mathrm{kg} /$ week x 10 weeks) generated the most prominent effect on iron load as indicated by the inter-group comparisons of SI and SF levels.

During detection of the peripheral hemogram, it was observed that peripheral WBC, RBC, hemoglobin and PLT were significantly decreased in group B and D1 compared with group A on day +10 . Bone marrow pathology also supported the successful establishment of the AA model: Groups B and D1 exhibited reduced areas of hematopoietic cells, increased proportions of adipocytes, and decreased megakaryocytes, indicating hematopoietic failure. The failure was more severe in group D1. Liver volumes and liver/body weight ratios were significantly higher in groups C1 and D1 than in the other two groups. Pathology also indicated marked increases in iron deposition in the bone marrow and liver tissues in groups $\mathrm{C} 1$ and D1. SI and SF levels were significantly higher in the three model groups compared with the group A. In addition, group D had a significantly higher SF level than group C, which indicated a higher iron load, possibly due to iron utilization disorders for bone marrow hematopoiesis. To confirm the stability of the composite model, the changes in SI and SF levels of group D1 mice on days +15 and +30 , and no significant differences were observed without continuing iron dextran.

Iron is transferred by divalent metal transporter 1 from ingested food to the cytoplasm of intestinal epithelial cells, where it is stored in SF or further transferred to blood plasma through ferroportin (FPN) on the basement membrane (28). Hepcidin, which is a vital factor for the regulation of iron metabolic balance in humans (29), has negative regulatory effects on the transportation of iron to the blood plasma through the combination with FPN to induce phosphorylation, endocytosis, and degradation of FPN in the cytoplasm (30). To date, the regulatory mechanisms of hepcidin expression, which are generally believed to be associated with the hemojuvelin (HJV)-BMP-SMAD signaling pathway, have not been completely clarified (31). HJV, which is a co-receptor of the BMP signal, is able to combine with the type $1 \mathrm{BMP}$ receptor to activate BMP. As a result, the phosphorylation of SMAD $1 / 5 / 8$ is promoted to combine with SMAD4 and form a complex that further enters the cell nucleus to stimulate hepcidin gene expression (32). TfR2 is predominantly expressed in liver cells and is able to positively regulate the BMP signaling pathway to upregulate hepcidin expression. The TfR 2 gene mutation is one of the causes of hereditary hemochromatosis (33).

Hepcidin level was previously reported to increase in patients undergoing transfusions due to iron overload and AA (34), which differed from the present results. The present study revealed the existence of iron metabolism disorders in mice of the AA and composite model groups, with a significantly lower hepcidin expression in the liver that corresponded to changes in BMP6, SMAD4, and TfR2. A possible explanation is that the AA model was formed in an acute pattern in the present study, and it is known that anemia may lead to a decrease in hepcidin, which may be ascribed to the feedback up-regulation of erythropoietin (15). In a previous mouse model of acute iron overload with intraperitoneal injection, hepcidin failed to appropriately respond to acute overload with iron dextran, and the hepcidin upregulation correlated with increased transferrin saturation (16). In the present study, group $\mathrm{C} 1$ had significantly lower expression levels of hepcidin, BMP6, and SMAD4 in the liver than group A, and significantly higher levels than groups B and D1. The association with iron overload would not further downregulate the negative parameters of iron deposition in AA mice when compared with the AA and composite model groups. These results suggest that AA may have a critical role in abnormal iron metabolism at the gene level, which promotes the development of iron deposits.

In conclusion, in the present study, a composite model of AA complicated with iron overload was successfully established through the combination of intraperitoneal injection of iron dextran and immune-mediated AA model. The established model is consistent with the clinical manifestations and pathogenesis of AA complicated by transfusion-induced iron overload. This successful model may help in the screening of iron chelation drugs and studies on pharmacological mechanisms.

\section{Acknowledgements}

The present study was supported by the Special Research Funds for Traditional Chinese Medicine Industry from State Administration of Traditional Chinese Medicine (grant nos. 201107001 and 201407001), Special Item of Important Disease of Zhejiang Province TCM Sic-Tech Innovation Platform (grant no. 2009ZDJB01) and Zhejiang Outstanding Young Talent Fund of Traditional Chinese Medicine (grant no. 2015ZQ013).

\section{References}

1. Young NS: Current concepts in the pathophysiology and treatment of aplastic anemia. Hematology Am Soc Hematol Educ Program 2013: 76-81, 2013.

2. Wu D, Shen Y, Ye B, Fang B, Lin S, Chen Z, Jiang H, Feng C, He HL, Gao Y, et al: Efficacy and advantages of modified Traditional Chinese Medicine treatments based on 'kidney reinforcing' for chronic aplastic anemia: A randomized controlled clinical trial. J Tradit Chin Med 36: 434-443, 2016.

3. Jin P, Wang J, Li X, Wang M, Ge M, Zhang J, Huang J, Zhang J, Huang Z, Nie N, et al: Evolution of iron burden in acquired aplastic anemia: A cohort study of more than 3-year follow-up. Int J Hematol 101: 13-22, 2015.

4. Bird RJ, Kenealy M, Forsyth C, Wellwood J, Leahy MF, Seymour JF and To LB: When should iron chelation therapy be considered in patients with myelodysplasia and other bone marrow failure syndromes with iron overload? Intern Med J 42: 450-455, 2012.

5. Takatoku M, Uchiyama T, Okamoto S, Kanakura Y, Sawada K, Tomonaga M, Nakao S, Nakahata T, Harada M, Murate T, et al: Retrospective nationwide survey of Japanese patients with transfusion-dependent MDS and aplastic anemia highlights the negative impact of iron overload on morbidity/mortality. Eur J Haematol 78: 487-494, 2007.

6. Killick SB, Bown N, Cavenagh J, Dokal I, Foukaneli T, Hill A, Hillmen P, Ireland R, Kulasekararaj A, Mufti G, et al: Guidelines for the diagnosis and management of adult aplastic anaemia. Br J Haematol 172: 187-207, 2016. 
7. Ampel NM, Bejarano GC and Saavedra M Jr: Deferoxamine increases the susceptibility of beta-thalassemic, iron-overloaded mice to infection with Listeria monocytogenes. Life Sci 50: $1327-1332,1992$

8. Karnon J, Tolley K, Oyee J, Jewitt K, Ossa D and Akehurst R: Cost-utility analysis of deferasirox compared to standard therapy with desferrioxamine for patients requiring iron chelation therapy in the United Kingdom. Curr Med Res Opin 24: $1609-1621,2008$

9. Pavenski K and Quirt I: The real cost of iron chelation therapy. Transfusion 47: 1751-1752, 2007

10. Viprakasit V, Lee-Lee C, Chong QT, Lin KH and Khuhapinant A: Iron chelation therapy in the management of thalassemia: The Asian perspectives. Int J Hematol 90: 435-445, 2009.

11. Institute of Laboratory Animal Resources (US): Committee on Care, Use of Laboratory Animals, and National Institutes of Health (US). Division of Research Resources: Guide for the care and use of laboratory animals. 7th edition. National Academies Press; Washington, DC, 1996.

12. Bär C, Huber N, Beier F and Blasco MA: Therapeutic effect of androgen therapy in a mouse model of aplastic anemia produced by short telomeres. Haematologica 100: 1267-1274, 2015.

13. Chai X, Li D, Cao X, Zhang Y, Mu J, Lu W, Xiao X, Li C, Meng J, Chen J, et al: ROS-mediated iron overload injures the hematopoiesis of bone marrow by damaging hematopoietic stem/progenitor cells in mice. Sci Rep 5: 10181, 2015.

14. Zhang Y, Zhai W, Zhao M, Li D, Chai X, Cao X, Meng J, Chen J, Xiao X, Li Q, et al: Effects of iron overload on the bone marrow microenvironment in mice. PLoS One 10: e0120219, 2015.

15. Wu D, Wang Q, Shen H, Xu H, Xu L and Zhou Y: 'Comanagement of Phlegm and Stasis' on the Apoptosis of Marrow Karyocyte in Mice with Aplastic Anemia and its Possible Mechanism. Zhonghua Zhong Yi Yao Za Zhi: 2080-2084, 2010 (In Chinese).

16. Swolin B, Simonsson P, Backman S, Löfqvist I, Bredin I and Johnsson M: Differential counting of blood leukocytes using automated microscopy and a decision support system based on artificial neural networks-evaluation of DiffMaster Octavia. Clin Lab Haematol 25: 139-147, 2003.

17. Livak KJ and Schmittgen TD: Analysis of relative gene expression data using real-time quantitative PCR and the 2(-Delta Delta C(T)) method. Methods 25: 402-408, 2001.

18. Suzuki T, Tomonaga M, Miyazaki Y, Nakao S, Ohyashiki K, Matsumura I, Kohgo Y, Niitsu Y, Kojima S and Ozawa K: Japanese epidemiological survey with consensus statement on Japanese guidelines for treatment of iron overload in bone marrow failure syndromes. Int $\mathrm{J}$ Hematol 88: 30-35, 2008.

19. Awai M: Pathogenesis and mechanism of iron overload: Ferric nitrilotriacetate, hemosiderin, active oxygen, and carcinogenesis. Rinsho Ketsueki 30: 1115-1127, 1989 (In Japanese).

20. Roderick JE, Gonzalez-Perez G, Kuksin CA, Dongre A, Roberts ER, Srinivasan J, Andrzejewski C Jr, Fauq AH, Golde TE, Miele L and Minter LM: Therapeutic targeting of NOTCH signaling ameliorates immune-mediated bone marrow failure of aplastic anemia. J Exp Med 210: 1311-1329, 2013.

21. Xu H, Zhang W, Zhang X, Ge X and Li J: Expression of PPARgamma in bone marrow of model mice of immune-mediated aplastic anemia mice model. Zhonghua Xue Ye Xue Za Zhi 35: 553-555, 2014 (In Chinese).
22. Wen X, Wu D, Ye B, Luuo Y, Wu F and Zhou Y: Overview of chronic iron-overloaded mouse models. Yi Xue Yan Jiu Za Zhi: 149-151, 2014 (In Chinese).

23. Italia K, Colah R and Ghosh K: Experimental animal model to study iron overload and iron chelation and review of other such models. Blood Cells Mol Dis 55: 194-199, 2015.

24. Hadziahmetovic M, Song Y, Wolkow N, Iacovelli J, Kautz L, Roth MP and Dunaief JL: Bmp6 regulates retinal iron homeostasis and has altered expression in age-related macular degeneration. Am J Pathol 179: 335-348, 2011.

25. Camberlein E, Abgueguen E, Fatih N, Canonne-Hergaux F, Leroyer P, Turlin B, Ropert M, Brissot P and Loréal O: Hepcidin induction limits mobilisation of splenic iron in a mouse model of secondary iron overload. Biochim Biophys Acta 1802: 339-346, 2010.

26. Gao Y, Wang N, Zhang Y, Ma Z, Guan P, Ma J, Zhang Y, Zhang X, Wang J, Zhang J and Chu L: Mechanism of protective effects of Danshen against iron overload-induced injury in mice. J Ethnopharmacol 145: 254-260, 2013.

27. Smith AG, Carthew P, Francis JE, Edwards RE and Dinsdale D: Characterization and accumulation of ferritin in hepatocyte nuclei of mice with iron overload. Hepatology 12: 1399-1405, 1990.

28. Xu Z, Sun W, Li Y, Ling S, Zhao C, Zhong G, Zhao D, Song J, Song H, Li J, et al: The regulation of iron metabolism by hepcidin contributes to unloading-induced bone loss. Bone 94: 152-161, 2017.

29. Saito H: Metabolism of Iron Stores. Nagoya J Med Sci 76: 235-254, 2014.

30. Détivaud L, Island ML, Jouanolle AM, Ropert M, Bardou-Jacquet E, Le Lan C, Mosser A, Leroyer P, Deugnier Y, David V, et al: Ferroportin diseases: Functional studies, a link between genetic and clinical phenotype. Hum Mutat 34: 1529-1536, 2013.

31. Lee DH, Zhou LJ, Zhou Z, Xie JX, Jung JU, Liu Y, Xi CX, Mei L and Xiong WC: Neogenin inhibits HJV secretion and regulates BMP-induced hepcidin expression and iron homeostasis. Blood 115: 3136-3145, 2010.

32. Wu XG, Wang Y, Wu Q, Cheng WH, Liu W, Zhao Y, Mayeur C, Schmidt PJ, Yu PB, Wang F and Xia Y: HFE interacts with the BMP type I receptor ALK3 to regulate hepcidin expression. Blood 124: 1335-1343, 2014.

33. Chen J and Enns CA: CD81 promotes both the degradation of transferrin receptor 2 (TfR2) and the Tfr2-mediated maintenance of hepcidin expression. J Biol Chem 290: 7841-7850, 2015.

34. Kaddah AM, Abdel-Salam A, Farhan MS and Ragab R: Serum hepcidin as a diagnostic marker of severe iron overload in beta-thalassemia Major. Indian J Pediatr: Jun 10, 2017 (Epub ahead of print).

This work is licensed under a Creative Commons Attribution-NonCommercial-NoDerivatives 4.0 International (CC BY-NC-ND 4.0) License. 